\title{
A Corpus Based Study on Cross Cultural Adaption of Websites of Foreign-Invested Enterprises in Heilongjiang Province
}

\author{
Jingbo Liu, Jinzhe Chu \\ Heilongjiang Bayi Agricultural University, Daqing, China \\ Email: qianchang_candice@163.com
}

How to cite this paper: Liu, J. B., \& Chu, J. Z. (2020). A Corpus Based Study on Cross Cultural Adaption of Websites of ForeignInvested Enterprises in Heilongjiang Province. Open Journal of Social Sciences, 8, 77-86.

https://doi.org/10.4236/jss.2020.83008

Received: February 11, 2020

Accepted: March 7, 2020

Published: March 10, 2020

Copyright $\odot 2020$ by author(s) and Scientific Research Publishing Inc. This work is licensed under the Creative Commons Attribution International License (CC BY 4.0).

http://creativecommons.org/licenses/by/4.0/

\begin{abstract}
Under the macro-environment of "The Belt and Road Initiative", Heilongjiang province receives more foreign investment since 2013. This paper endeavors to collect website information of foreign-invested companies in Heilongjiang province and Heilongiiang local companies and build two corresponding corpuses. After analyzing data by using WMATRIX 4 tool, the author selects semantic clouds under the framework of Singh's website content. Then after comparing data of Heilongjiang local companies and foreign invested companies in Heilongjiang province, the author tries to explain the data from Hofstede's cultural dimensions, namely, individualism vs. collectivism, power distance, uncertainty avoidance and femininity vs. masculinity. Then suggestions on the website building to adapt to the local culture have been made. The study makes a useful attempt to explore the effectiveness of business communication across disciplines by using linguistic research perspectives and research methods.
\end{abstract}

\section{Keywords \\ Corpus, Cross Cultural Adaption, Company Website}

\section{Introduction}

After China initiated "The Belt and Road Initiative" in 2013, foreign countries have deepened their relationship with China, especially in economic aspect. Foreign companies invest more money in China to establish factories, offices and so on. In 2015, focusing on the construction of China-Mongolia-Russia Economic Corridor, Heilongjiang Province drew up the China-Mongolia-Russia Economic Corridor Construction Plan of Heilongjiang Land and Maritime Silk Road Economic Belt. In 2017, 103 foreign-invested enterprises were newly established in 
Heilongjiang Province; and the actual utilized foreign capital totaled 5.84 billion U.S. dollars, up 0.3 percent (Xinhua News, 2018). There were foreign-invested enterprises from 26 countries and regions investing in Heilongjiang province in 2017. The actual utilized foreign funds reached 481.82 billion yuan, increased by 7.7 percent (Xinhua News, 2018). However, the websites they designed are differentiated by culture and the effects largely depend on the satisfaction of local customers (Halliburton \& Ziegfeld, 2009). In order to expand their business in China, these companies have to understand the need of customers in China and remove the language obstacles on their websites (Pollach, 2005).

Previous studies mainly focus on the business perspective like Jiang, Jiang \& Wei (2014) investigated this issue from public relations but few concentrate on the language part of the website. However, language is the major source of information that customers could get from the website. Website localization from the cultural perspective is an urgent issue under the background of "The Belt and Road Initiative". In order to enrich the research vision in this field, this paper combines the applied linguistic theories such as business discourse and cross-cultural communication, with the help of corpus tool WMATRIX 4, compares the language cultural characteristics of English websites of Chinese and foreign invested enterprises in Heilongjiang province, analyzes the localization level of English websites of Chinese enterprises, and then discusses from which aspects of business discourse of Chinese corporate websites can make cross-cultural adjustment and related research implications.

\section{Theoretical Framework}

This paper intends to use Hofstede's cultural dimension and Singh's website content framework. In Hofstede's well-known and widely-accepted model of national cultures, Geert Hofstede introduced four dimensions that have been used extensively in national culture research. These dimensions, which are to be seen as continuum, are as follows: power distance, uncertainty avoidance, individualism versus collectivism and masculinity versus femininity (Hofstede, 1991). In his later study with Bond on twenty-three countries, Hofstede added a fifth dimension that sought to describe a long-term orientation in life as opposed to a short-term orientation. However, this paper mainly focuses on the following dimensions. Individualism versus collectivism focuses on the degree to which the society reinforces individual or collective achievement and interpersonal relationships. A high individualism ranking indicates that individuality and individual rights are paramount within the society. A low individualism ranking typifies societies of a more collectivist nature with close ties between individuals. Masculinity versus femininity refers to the distribution of roles between men and women. Based on Hofstede's cultural dimensions, Sing categorizes web site contents accordingly.

\section{Research Methods}

This paper intends to collect 30 company profiles of Heilongiang local compa- 
nies and foreign companies with investment in Heilongjiang Province by 4 Feb. 2020. The author chooses "about us" part of the company to analyze the semantic cloud since this part main includes business scope, business location, key consumer and so on. The business scope of most companies is manufacturing, medicine, food. Then the author excludes pictures and videos of the website to get the text content and build up two corpuses accordingly. The semantic field will be compared to BNC Sampler CG business corpus. The data will be tagged with WMATRIX 4 tool.

Through empirical research, this study will try to answer the following questions: 1) Is there any significant cultural difference in the business discourse of the English websites of Chinese and foreign invested enterprises in Heilongjiang province? 2) What are the similarities and differences between the iconic business discourse of the English websites of Chinese and foreign invested enterprises in Heilongjiang province? 3) From what angles can foreign invested enterprises in Heilongjiang province optimize the localization level of their English websites?

\section{Data Analysis}

According to the results of WMATRIX 4and Singh's website content framework (Singh \& Baack, 2004), the data will be analyzed as follows.

Many foreign companies located in Heilongjiang Province are invested by European or American countries so the paper uses cultural dimension of America and China to make a comparison.

Based on Table 1, it is assumed that in terms of Individualism vs. Collectivism, Chinese companies use more words to show the importance of belonging, community, social welfare and so on. For Power distance, Chinese companies will use more words to emphasize on government, control, etc. From the perspective of uncertainty avoidance, foreign companies will focus on product safety, customer service, etc. For masculinity vs. femininity, Heilongjiang local companies will reflect a higher level of masculinity than American companies.

\subsection{Individualism vs. Collectivism}

This dimension involves community relations like presence or absence of community policy, giving back to community, social responsibility policy and family theme such as pictures of family, pictures of teams of employees, mention of employee teams and emphasis on team and collective work responsibility in vision statement or elsewhere on the Web site, and emphasis on customers as a family. The study extracts "green issues, belonging to a group, selfish" semantic clouds.

From Table 2, we know that both Chinese companies and foreign companies use many words to describe information about environmental protection and few words to describe selfish semantic word cloud, which reflects that corporate social responsibility (CSR) has won more recognition in both Chinese and foreign-invested companies. CSR played a more important role in company image 
Table 1. Cultural dimension of America and China.

\begin{tabular}{ccccc}
\hline & $\begin{array}{c}\text { Individualism } \\
\text { versus collectivism }\end{array}$ & Power distance & $\begin{array}{c}\text { Uncertainty } \\
\text { Avoidance }\end{array}$ & $\begin{array}{c}\text { Masculinity versus } \\
\text { femininity }\end{array}$ \\
\hline China & 20 & 80 & 30 & 66 \\
America & 91 & 40 & 46 & 62 \\
\hline
\end{tabular}

Table 2. Result in WMATRIX of individualism \& collectivism dimension.

\begin{tabular}{ccccccc}
\hline \multirow{2}{*}{ Semantic Cloud } & \multicolumn{3}{c}{ Foreign companies } & \multicolumn{3}{c}{ Chinese companies } \\
\cline { 2 - 7 } & rank & frequency & Log ratio & rank & frequency & Log ratio \\
\hline Green Issues & 53 & 4 & 2.89 & 45 & 8 & 3.07 \\
Belonging to a Group & 116 & 32 & 0.23 & 47 & 80 & 0.73 \\
Selfish & 142 & 1 & 1.46 & 91 & 4 & 0.28 \\
\hline
\end{tabular}

and competitive power (Fatma \& Rahman, 2014). In this dimension, Chinese companies reflect a higher level of collectivism the same as the assumption. Chinese companies use more words to illustrate "green issues" and "belonging to a group" semantic word clouds to create self-in-relation-to-others and group consensus appeal and family integrity (Lin, 2001). "Selfish" semantic cloud is used to depict individualism dimension so the more it is used; the more individualism companies display. Both foreign-invested companies and Chinese companies apply a few of them just to have a better publicity. Chinese companies use a little more "selfish" semantic cloud by employing words such as "take pride in", "boast" and so on, which in contradiction with the previous assumption.

For instance,

1) We take pride in providing your family with furniture that will create a home filled with love and comfort. - Cargill

2) ABB promotes the cultivation of local talents by holding the annual Innovation Contest and participates in various charity activities, such as planting trees, volunteering in communities, caring for senior citizens and hosting electrical safety seminars. - ABB

3) All these products have been approved to be qualified and "Environmental Friendliness Product" by Heilongjiang provincial authorities. - Heilongjiang Chia Tai Co. Ltd.

In example 1, Cargill employs "take pride in" to show the effort it makes on providing furniture. This category of words belongs to individualism dimension. Example 2 and 3 elaborates that community and environmental awareness have been improved so these words have been used often.

\subsection{Power Distance}

Societies that are high on power distance, such as China, Mexico, and India, accept power and hierarchy in society and are low on egalitarianism. The emphases in high power distance societies are on status, referent power, authority, and 
legitimacy. So, this dimension collects semantic data about "government", "in power", "respected" to discuss power distance dimension.

The data from Table 3 shows that Chinese companies use more "government" related semantic cloud such as "governmental", "authority", "official" since China ranks high on power distance, like Harbin Aircraft Industry Group emphasizes "...with the approval of the Chinese and French governments..." to show the great influence of government on companies' decision making. Still, words like "supervision", "control", "manage" and so on appear more often in Chinese companies' websites. Also, Chinese companies have a higher frequency in this category because China culture values a higher power distance than Foreign countries as the following example shows us.

HLG is consistently certificated year after year by Administration of quality supervision, inspection and quarantine of China (AQSIQ) and Heilongjiang Province Safety Production Supervision Administration. - Harbin LiGong Chemicals (HLG) Co. Ltd.

However, the "respected" semantic cloud shows nearly no clear difference between Chinese companies and foreign-invested companies. "Respect" means that People have to agree the authorities and well-known people. Companies just use this category of words to show the social influence of them. For instance, Volvo Cars are one of the most well-known and respected premium car brands. Both categories of companies seldom use this semantic cloud since the recognition is gained from customers, not by companies themselves.

\subsection{Uncertainty Avoidance}

Uncertainty avoidance relates to the extent to which the people of a country can tolerate ambiguous or uncertain situations. Countries like Greece, Japan, and Mexico rank high on uncertainty avoidance, and their people are relatively more risk averse, need security, and look for direction. The uncertainty avoidance dimension is operationalized as the depiction of customer service, guided navigation, tradition theme, local terminology, free trials and downloads, customer testimonials, and toll-free numbers. This operationalization is based on the concept that in uncertainty avoidance culture, individuals avoid ambiguous situations and seek advice, security, and guidance to feel at ease (Gudykunst, 1998). So, in this dimension the author focuses on "safe", "helping", and "Time: New and young".

From Table 4, it is known that foreign-invested companies tend to use more words to create a sense of safety for customers, they use words like "safe", "safety" since foreign countries have a higher ranking on uncertainty avoidance than China. Safety not only refers to the company itself, but the product or services it offers according to Huang et al.'s (2009) evaluating model of Corporate Social Responsibility such as following example.

Strictly control varieties of indexes of the raw material to guarantee the quality and safety. - Harbin Zhongan Making Oil Co. Ltd. 
Table 3. Result in WMATRIX of power distance dimension.

\begin{tabular}{ccccccc}
\hline \multirow{2}{*}{$\begin{array}{c}\text { Semantic } \\
\text { Cloud }\end{array}$} & \multicolumn{3}{c}{ Foreign companies } & \multicolumn{3}{c}{ Chinese companies } \\
\cline { 2 - 7 } & rank & frequency & Log ratio & rank & frequency & Log ratio \\
\hline Government & 69 & 13 & 0.92 & 46 & 30 & 1.3 \\
In power & 51 & 40 & 0.76 & 36 & 81 & 0.96 \\
Respected & 64 & 3 & 2.48 & 65 & 5 & 2.39 \\
\hline
\end{tabular}

Table 4. Result in WMATRIX of uncertainty avoidance dimension.

\begin{tabular}{ccccccc}
\hline \multirow{2}{*}{ Semantic Cloud } & \multicolumn{3}{c}{ Foreign companies } & \multicolumn{3}{c}{ Chinese companies } \\
\cline { 2 - 7 } & rank & frequency & Log ratio & rank & frequency & Log ratio \\
\hline safe & 40 & 7 & 2.95 & 96 & 4 & 1.31 \\
$\begin{array}{c}\text { helping } \\
\text { Time: New and } \\
\text { young }\end{array}$ & 21 & 47 & 1.44 & 67 & 47 & 0.61 \\
\hline
\end{tabular}

Meanwhile, "helping" is another semantic field that companies use to avoid risk according to Sing's framework in which customer Service: FAQ's, customer service option, customer help, customer contact or customer service e-mails will be emphasized. Words like "serve", "help", "support" are used to maintain the relationship with customers. Still, foreign-invested companies have a higher ranking of this category usage than Heilongiiang local companies because of the ranking in uncertainty avoidance.

We help livestock and aquaculture farmers, feed manufacturers and distributors of all sizes deliver better animal nutrition through unparalleled research capabilities, innovative feed and premix products and services, and digital modeling and formulation solutions. - Cargill

Under Sing's framework, tradition theme with an emphasis on history and ties of a particular company with a nation will decrease customers' uncertainty. The opposite semantic field is "new and young". Foreign-invested companies rank higher in this category. This result is not what we assumed previously. By referring to a specific example, it is known that $A B B$ has invented a new kind of product. As previously mentioned, companies collected are mainly in the business scope of manufacturing, medicine, food so that it is important to have new innovations and new products or services. So, both local companies and foreign-invested companies use "new and young" semantic word cloud frequently.

The ABB China R \& D team has led or participated in the research and development of smart sensors, $1100 \mathrm{kV}$ UHVDC transformer, $800 \mathrm{kV}$ GIS, new type of ring main unit (RMU), dual-arm robot $\mathrm{YuMi}^{\oplus}$, $\mathrm{i}$-Jia smart home system. $-\mathrm{ABB}$

\subsection{Masculinity vs. Femininity}

Masculine cultures value assertiveness, ambition, success, and performance. To 
such cultures big and fast is beautiful, the machismo ideal is acceptable, and clear gender roles are the norm. In contrast, feminine cultures value, beauty, nature, nurturance, the machismo ideal is not acceptable, and gender roles are blurred. Countries such as Japan, Austria, and Mexico are examples of masculine cultures, while most of the Nordic countries score high on femininity. According to Sing's website framework, the use of superlatives including the use of superlative words and sentences like "We are the number one" "The top company" "The leader" "World's largest" is a signal to show masculinity. Product effectiveness such as durability information, quality information, product attribute information, and product robustness information are also an indicator of masculinity. So, the author chooses "Evaluation: Good", "Evaluation: Good/bad" (actually, this category shows quality information after a deeper examination) and "Tough/strong" semantic cloud to investigate the data.

From Table 5, it is known that foreign-invested companies rank lower in "Evaluation: Good" compared with Heilongjiang local companies since China has a higher masculinity ranking. Chinese companies tend to use more words to show their status in the industry and to compare the related companies. For example, Harbin Pharmaceutical Group Co., Ltd. uses "most" and other superlatives to show its influence on pharmaceutical industry.

HPGC has received honors and awards including "Winner of Chinese Top 100 Pharmaceutical Companies", "China’s Most Respected Enterprise”, "Champion of the Global Top 100 Chinese Companies”, "China's Innovative Company with the Most Growth Potential", "Harbin Top 50 Taxpayers of Industry Companies", "the Top 10 Most Influential Pharmaceutical Enterprise Award", and "Key High-Tech Enterprise of National Torch Plan". — Harbin Pharmaceutical Group Co., Ltd.

Heilongiiang local companies also emphasize more on the product quality which is related to a higher power dimension. Authorities in China play a more important role to supervise quality issue. Take the following examples for an overview, Long Jian Road and Bridge Co., Ltd. focuses on the social prestige and project quality to get the public's recognition.

All the projects have earned a high reputation from owners and experts by virtue of good prestige and creditable quality. - Long Jian Road and Bridge Co., Ltd.

Foreign invested companies and Chinese companies both use a few strict/strong words and Heilongjiang local companies employ a high proportion of this

Table 5. Result in WMATRIX of masculinity \& femininity dimension.

\begin{tabular}{ccccccc}
\hline \multirow{2}{*}{ Semantic Cloud } & \multicolumn{3}{c}{ Foreign companies } & \multicolumn{3}{c}{ Chinese companies } \\
\cline { 2 - 7 } & rank & frequency & Log ratio & rank & frequency & Log ratio \\
\hline Evaluation: Good & 31 & 12 & 2.46 & 19 & 25 & 2.69 \\
Evaluation: Good/bad & 74 & 14 & 0.81 & 20 & 46 & 1.70 \\
Tough/strong & 73 & 4 & 1.68 & 60 & 9 & 2.03 \\
\hline
\end{tabular}


category of words. However, a closer investigation into the data will find that Chinese companies use more "strict" word cloud to show its obedience to laws and regulations, closely related to power distance dimension while foreign invested companies use more "strong" word cloud to show its performance. For example, Harbin Zhongan Making Oil Co., Ltd. uses "strictly" to show the compliance with international standard.

We strictly follow the international standard, focusing on every detail, holding the thought of quality is everything and producing the soya expeller meal that admitted by the customers. - Harbin Zhongan Making Oil Co. Ltd.

\section{Findings}

From the data analysis, it is known that in collectivism vs. individualism dimension, Heilongjiang local companies use more words to describe "green issues", "belonging to a group" and "selfish" semantic clouds. This reminds foreign companies to pay more attention to corporate social responsibility when introducing themselves to the website. For the dimension of power distance, Chinese companies use more words related to "government" and "in power" while similar words related to "respected" compared with foreign invested companies. It is recommended that foreign invested companies attach more importance to governments and authorities, using words to improve its publicity and build up confidence in customers. In terms of uncertainty avoidance dimension, foreign invested companies tend to focus more on "safe", "helping" and "time: new and young". Heilongjiang local companies do not have the safety recognition and have more trust on authorities. So foreign-invested companies can refer more to governments and authorities' regulations which will gain customers' trust instead of using more words to describe the product safety. For masculinity vs. femininity dimension, Heilongjiang local companies use more words to describe "evaluation: good" and "Evaluation: Good/bad" to show their status in the industry and their products' excellent quality. It is recommended that foreign invested companies evaluate their companies or product more especially on quality prospect to have a greater influence on the industry and their target customers.

\section{Conclusion}

The paper endeavors to study company website from a cross-cultural view based on corpus linguistic approach. Through quantitative and qualitative analysis, the author compares similarities and differences of Heilongjiang local companies and foreign invested companies in Heilongjiang province within Hofstede's cultural dimensions and makes further suggestions on cross-cultural adaption of foreign invested companies in Heilongjiang province.

Chinese companies' websites were more collectivist, more masculine, and exhibited higher power distance. Similar to the above findings, foreign-invested companies exhibited higher uncertainty avoidance. The findings indicate that 
when the local websites of two culturally distant countries are examined, their content strongly reflects the specific culture in which it was created. Therefore, we can conclude that the Web reflects cultural values.

Great implication can be inferred from the study that even though English is the same language both Chinese companies and local companies use, significant cultural differences can be observed. How to make a better cross-cultural adaption in international business communication is worthy of further discussion. Under the macro-environment of "The Belt and Road Initiative", more foreign investment has been made into Heilongiiang province. The paper is a useful practice to improve communication effectiveness and cross-cultural adaption for foreign investors. Though this paper has some limitation like the limitedness of data sources and choice of semantic cloud, it is hoped that this study provides reference for further study on international business communication, website construction and research on English for Specific Purpose teaching.

\section{Acknowledgements}

This paper belongs to the achievements in "Heilongjiang Bayi Agricultural University Support Program for San Heng San Zong” (Project No. RRCPY201912).

\section{Conflicts of Interest}

The authors declare no conflicts of interest regarding the publication of this paper.

\section{References}

Fatma, M., \& Rahman, Z. (2014). Building a Corporate Identity Using Corporate Social Responsibility: A Website-Based Study of Indian Banks. Social Responsibility Journal, 10, 591-601. https://doi.org/10.1108/SRJ-01-2013-0002

Gudykunst, W. B. (1998). Bridging Differences: Effective Intergroup Communication (3rd ed.). Thousand Oaks, CA: Sage Publications.

Halliburton, C., \& Ziegfeld, A. (2009). How Do Major European Companies Communicate Their Corporate Identity across Countries? An Empirical Investigation of Corporate Internet Communications. Journal of Marketing and Management, 25, 909-925. https://doi.org/10.1362/026725709X479291

Hofstede, G. (1991). Cultures and Organizations: Software of the Mind. London: Mcgraw-Hill.

Huang, Q. H., Peng, H. G., Zhong, Y. W., \& Zhang, E. (2009). Evaluating the Level of Responsibility Management and CSR Information Disclosure of Top 100 Companies in China. China Industrial Economies, No. 10, 23-35.

Jiang, J., \& Wei, R. (2014). Cultural Variations and Mediated Organization-Public Relationship Building: A Content Analysis of U.S and Chinese Corporate Websites. Chinese Journal of Journalism \& Communication, No. 8, 105-110.

Lin, C. A. (2001). Cultural Values Reflected in Chinese and American Television Advertising. Journal of Advertising, 30, 83-94. https://doi.org/10.1080/00913367.2001.10673653

Pollach, I. (2005). Corporate Self-Presentation on the WWW: Strategies for Enhancing 
Usability, Credibility and Utility. Corporate Communications: An International Journal, 10, 285-301. https://doi.org/10.1108/13563280510630098

Singh, N., \& Baack, D. W. (2004). Web Site Adaptation: A Cross-Cultural Comparison of US and Mexican Web Sites. Journal of Computer-Mediated Communication, 9. https://doi.org/10.1111/j.1083-6101.2004.tb00298.x

Xinhua News (2018). Heilongjiang Business Environment Assessment Report 2018. http://upload.silkroad.news.cn/2018/0904/1536024478115.pdf 